\title{
Evidence of a changing size-frequency distribution of landslides in the Kyrgyz Tien Shan, Central Asia
}

\author{
Romy Schlögel, ${ }^{1 *}$ Isakbek Torgoev, ${ }^{2}$ Cédric De Marneffe ${ }^{1}$ and Hans-Balder Havenith ${ }^{\mathbf{1}}$ \\ ${ }^{1}$ Georisks and Environment, Department of Geology, University of Liège, Belgium \\ ${ }^{2}$ SEC Geopribor, Institute of Geomechanics and Development of Subsoil, Bishkek, Kyrgyz Republic
}

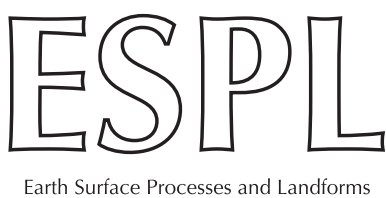

\begin{abstract}
There is a strong possibility that environmental change (whether climate or land use) will be manifest as changes in the size-frequency distribution of landslides. Here, evidence is presented for this from western Kyrgyzstan, Central Asia. Remote sensing and spatial analysis have been applied to map mass movements in the central part of the Maily-Say Valley and to detect recent landslide activations. The evolution of landslide activity over the past 50 years has been analysed on the basis of pre-existing landslide maps and new analyses of aerial photographs as well as Quickbird images. Five inventories were produced for the years 1962 (based on the existing map of 1962 and aerial photographs of 1962), 1984 (based on the existing map of 1977 and aerial photographs of 1984), 1996 (based on aerial photographs of 1996), 2002 (based on the existing map of 2003 and Quickbird imagery of 2002) and 2007 (based on Quickbird imagery of 2007). The geomorphologic features contained in the catalogues represent the landslide bodies observed from remote imagery of the corresponding year. Mapped landslides are generally considered as the result of a series of slope failure events. Size-frequency analyses applied to the five landslide inventories show that both the number and size of unstable slopes increased from 1962 (162 objects) to 2007 (208 objects) and the power-law exponent decreased over time. This changing power-law exponent may indicate that landslide-related hazards are increasing. This tendency is documented in more detail for two active landslide zones, one in the main valley and one located to the west of it. Landslide detection methods were used to assist the evolution of slope instabilities. Choosing appropriate thresholds, the image subtraction method based on normalized difference vegetation index (NDVI) allowed accurate detection of new sliding activation in these two zones. This confirmed the results of the more extensive survey that there is a systematic shift in power law exponents and size-frequency distributions for Central Asian landslides. Copyright (c) 2011 John Wiley \& Sons, Ltd.
\end{abstract}

KEYWORDS: landslide activity; frequency density function; image subtraction; normalized differenced vegetation index; Kyrgyzstan

\section{Introduction}

Kyrgyzstan is prone to many natural hazards due to high seismicity, active tectonics, glacier retreat, and locally intense rainfall (Torgoev et al., 2002). These long- and short-term factors contribute to the occurrence of frequent mass movements, which kill many people each year, especially in the southern part of the country along the rim of the Fergana Basin (Roessner et al., 2002), including the Maily-Say Valley (Figure 1). Owing to the high landslide activity in this area and the presence of numerous nuclear waste storage facilities along the Maily-Say River, the geological hazard and consequent ecological and societal risks are high (Vandenhove et al., 2003). This is evidenced by two examples: in 2003, the Bedre landslide in the western part of the valley killed two people; the regular activation of the main scarp of the Tektonik landslide (marked by a $16 \mathrm{~m}$ vertical displacement over the last 9 years) is accompanied by the damming of the Maily-Say river below, which causes upstream- and downstream flooding and sometimes pollution from nuclear deposits (Torgoev et al., 2002; Havenith et al., 2006).
This paper addresses landslide hazard in the central part of the Maily-Say Valley through analysis of general landslide activity and specific consideration of two mass movement case histories. According to Torgoev et al. (2002), the number of large landslides clearly increased from 1950 to 2001, after the start of uranium mining activities in 1946 in the Maily-Say Valley. On the basis of digitized existing landslide maps of 1962, 1977, and 2003, as well as new analyses of aerial photographs of 1996 and satellite imagery of 2002 and 2007, landslide evolution is studied by simple statistics and sizefrequency computations using the 'landslide frequency-area distributions' method proposed by Malamud et al. (2004).

Remote sensing analyses were applied to high-resolution Quickbird images (BGIS 2000 sensor) to map all landslides in the central part of the valley that could be identified in 2002 and 2007. The imagery contains textural and spectral information that can be very useful to detect particular landslide features such as scarps, flows, and ground cracks, and are particularly valuable when large- to moderate-scale aerial photography is lacking (Rathje et al., 2006; Yang et al., 2008). Regional landslide mapping has been performed using 


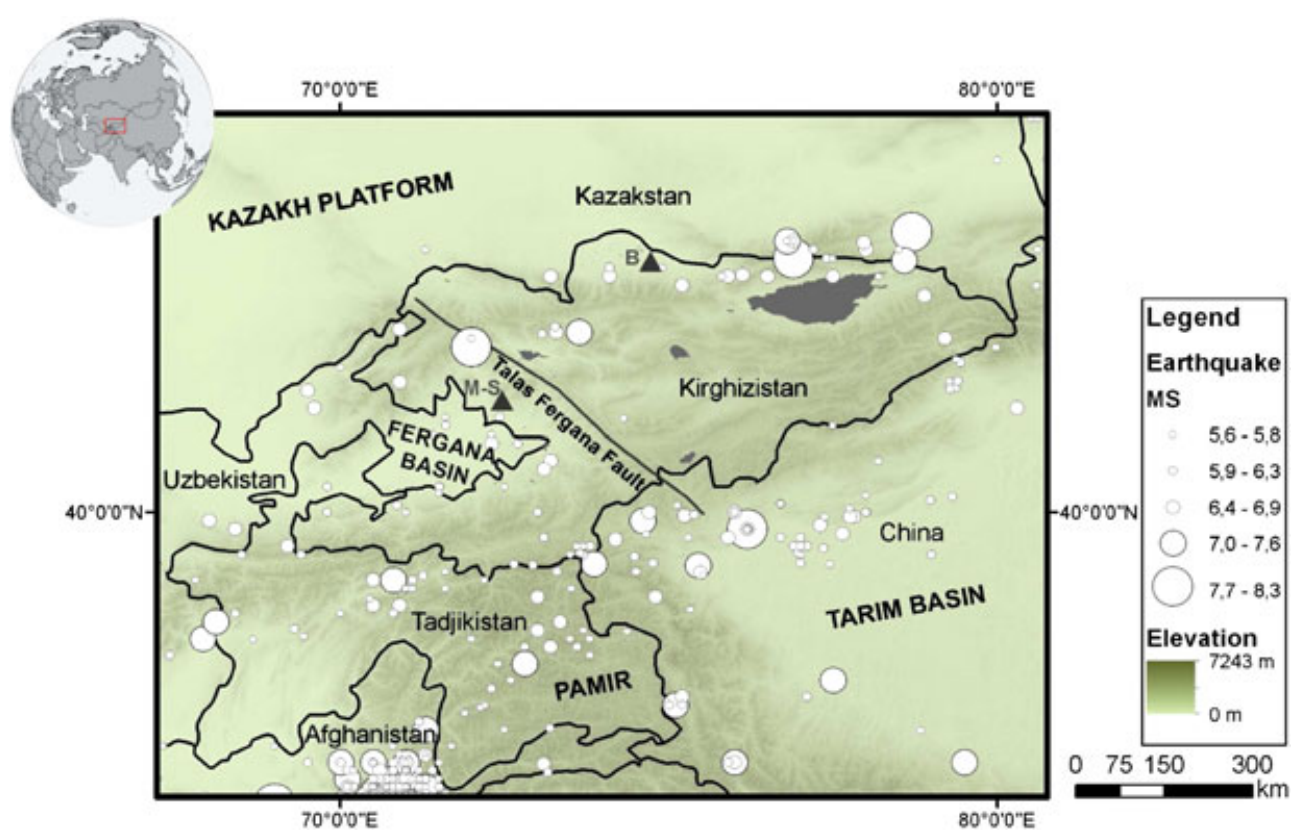

Figure 1. Topographic map of the Kyrgyz Tien Shan and neighbouring regions. The location of Maily-Say (M-S) and the capital city (Bishkek) is indicated by a black triangle. The map also shows all historical and instrumental earthquake events with Ms $>5.5$. This figure is available in colour online at wileyonlinelibrary.com/journal/espl

a uni-temporal approach; methods of change detection based on image differencing have been applied to particular unstable zones in order to define newly activated and re-activated landslides. Subtraction has been applied to previously calculated normalized difference vegetation index (NDVI) maps in order to define the landslide activity between 2002 and 2007. The image differencing method is widely used for assessment of natural hazards, including landslides (Chang and Liu, 2004).

\section{Study Area}

The Maily-Say Valley is situated in the north of the Fergana Basin (approximately $41.1^{\circ} \mathrm{N}$ and $72.5^{\circ} \mathrm{E}$ ), $60 \mathrm{~km}$ north-west of Jalal-Abad and about $25 \mathrm{~km}$ from the border with Uzbekistan (Figure 1). It is located in a transitional zone bounded in the north-east by the Talas-Fergana Fault. Climatic conditions are semi-arid and land cover is mixed woodland-grass. Bedrock geology is constituted of Cenozoic and Mesozoic sedimentary rocks (Vandenhove et al., 2003; Havenith et al., 2006).

Over recent decades, the town of Maily-Say (estimated population 10,000 ) has experienced a series of environmental disasters related to earthquakes, landslides, and groundwater pollution (in particular by radioactive material). According to Abdrakhmatov et al. (2003), the seismic hazard of the region is moderate to high. The last strong earthquake (Ms 6.2) hit the region on 15 May 1992, and was located about $30 \mathrm{~km}$ south-south-east of the town of Maily-Say.

Evidence for the high landslide activity and slope instability is observed throughout the area (Figure 2); landslides in the area cause significant damage to houses and infrastructure and kill people almost every year (information provided by authorities). According to a previous report by Minetti (2004), 210 landslides are located in the vicinity of the town, 80 of which are unstable and have the potential to move under adverse conditions.

The largest landslide in the region, located about $7 \mathrm{~km}$ east of the town of Maily-Say, is the Kochkor-Ata landslide, which failed as one unit, on 13 April 1994, forming an almost $4 \mathrm{~km}$ long earth flow with a total volume of about $10 \mathrm{Mm}^{3}$ (Roessner et al., 2002).

\section{Methods}

\section{Digital datasets and pre-processing}

Multi-temporal, remotely sensed images were collected to detect landslides and to determine their evolution. Available aerial photographs of 1962, 1984, and 1996 (panchromatic, scanned at $600 \mathrm{dpi}$, roughly $2 \mathrm{~m}$ ground-resolution, approximate 1:21,000 scale stereo-coverage) for the Maily-Say Valley were studied in detail and compared with panchromatic and multi-spectral 10.3 by $11.1 \mathrm{~km}$ Quickbird images of 2002 (13 July 2002, 12:06 PM, local time) and 2007 (26 June 2007, 12:20 PM, local time). The multi-spectral images provide four spectral bands (blue, 0.450-0.520 $\mu \mathrm{m}$; green, $0.520-0.600 \mu \mathrm{m}$; red, $0.630-0.690 \mu \mathrm{m}$; near-infrared, $0.760-0.900 \mu \mathrm{m})$ with a spatial resolution of $2.44 \mathrm{~m}$; panchromatic Quickbird images have a spatial resolution of $0.61 \mathrm{~m}$.

Quickbird imagery was pre-processed with the ENVI software before being classified (unsupervised) through image subtraction in order to make radiometrically and geometrically comparable 2002 and 2007 scenes. Factors affecting geometry can be related to the sensor system, due to variations in platform altitude, in the sensor look angle or caused by rotation of the earth (Gupta, 2003). For the fixed orbit of Quickbird, only the true distance changes as a function of the look angle of the sensor at the time of data acquisition. The images were orthorectified on the basis of a $20 \mathrm{~m}$ resolution Satellite Pour I'Observation de la Terre (SPOT) digital elevation model (DEM) and georeferenced to UTM zone 43 north. Panchromatic and multi-spectral images were co-registered separately to allow superimposition of multi-spectral images. In addition, the images were normalized using a relative radiometric correction process on the basis of assumed pseudo-invariant features or PIFs (Du et al., 2002). The normalization was accomplished on a band-by-band basis using these PIFs with a linear regression. Gains and offsets were applied to create a normalized image of the 2007 scene while the $2002 \mathrm{im}$ age is taken as reference because it presents larger contrasts (Jensen, 1996). 


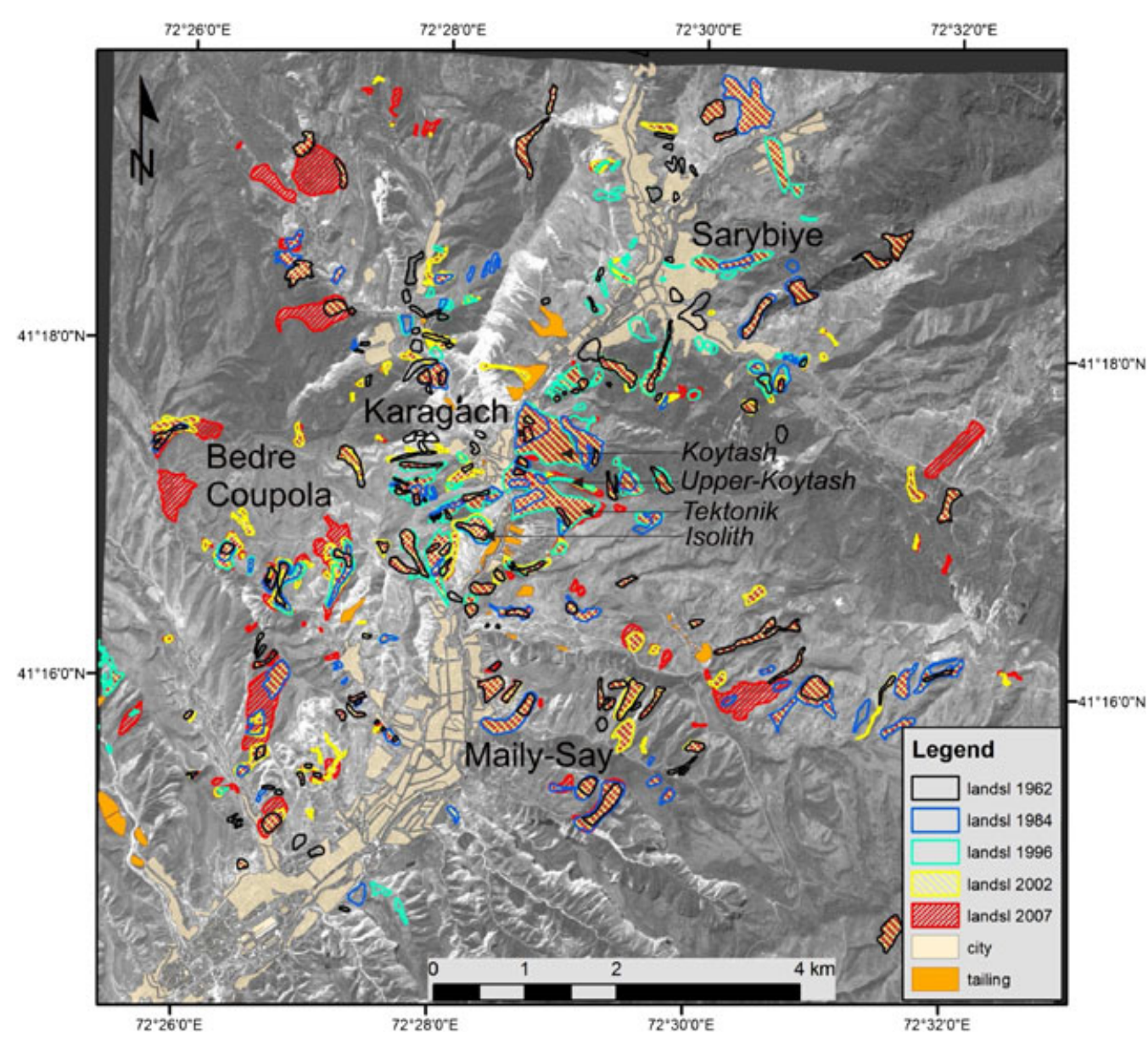

Figure 2. Map showing the 2002 panchromatic Quickbird image of the Maily-Say Valley, the physiographic area of the Bedre Coupola as well as the location of populated places (Maily-Say, Karagash and Sarybiye) and nuclear waste tailings and outlines of landslides digitized for 1962, 1984, 1996, 2002 and 2007 including the well-known landslides (Koytash, Upper-Koytash, Tektonik, Isolith). This figure is available in colour online at wileyonlinelibrary.com/journal/espl

\section{Landslide inventories}

Landslide inventories are the simplest form of landslide susceptibility mapping (Guzzetti et al., 1999). Two new landslide inventories were created from the Quickbird images for the Maily-Say Valley and verified by field observations (Figure 2). Using geographical information system (GIS) tools, a total of 189 and 208 landslides were mapped from 2002 and 2007 images, respectively. The new landslide inventory of 2002 replaces an existing landslide map of 2003 (220 mapped landslides, presented by Havenith et al., 2006), which could not be verified because of missing remote sensing data. Therefore, it was decided to consider only the new 2002 inventory, which, however, includes all landslides mapped in 2003 that could be observed from the 2002 Quickbird image.

The first map of landslides of this region dates back to 1962 (78 landslides, already used by Havenith et al., 2006). This map was recently completed by observations from aerial photographs of 1962, which finally allowed us to map a total of 162 slopes marked by landslide phenomena in 1962. The second existing landslide map of 1977 (117 mapped landslides, also used by Havenith et al., 2006) was combined with analyses of aerial photographs of 1984 to produce a new inventory for 1984 (206 objects). Aerial photographs of 1996 allowed us to compile a new landslide catalogue for the year 1996 (222 objects). All five inventories contain only landslides that could be identified from remote imagery of a certain year and, thus, are likely to have been (re-)activated in recent times (ancient mass movements have not been included in those catalogues). Thus, the mapped landslides represent objects and not sliding processes or events; they are rather the result of a series of landslide activations. Historical information on individual landslide events was not available to complete the inventories. The initial inventories were created by local scientists through field surveys and air photo interpretation, and corrected by comparison with recent data to make them accurate and comparable (Brardinoni et al., 2003). The number of landslides presented in Havenith et al. (2006) was corrected, as part of the work presented here. Some interpretations of these black and white photographs $(1: 21,000$, approximately $2 \mathrm{~m}$ resolution) were done with the stereoscope. The Quickbird images were draped over the $20 \mathrm{~m}$ DEM in ArcScene (perspective mode) to identify slope failures better. For landslide mapping, they were also classified in terms of NDVI and the differences between 2002 and 2007 NDVI values (as described below). The catalogue of 2003, derived only from field observations, described in Havenith et al. (2006) was replaced by the 2002 map, which could be better verified on the basis of the 2002 Quickbird image.

The types of landslides that are most easily detected are fresh earth flows, debris flows, and, to a minor degree, debris falls. The greater ability to detect these landslides could be related to morphologic and spectral reflectance differences along discrete boundaries that result from their shallow, disrupted, and rapid nature (several meters or tens of meters per year). Deep-seated and slow (cm/year to $\mathrm{m} /$ year), generally rotational slides marked by weaker changes of the surface have different morphology and reflectance properties. For example, the deep-seated and slowly moving Koytash landslide on which the hamlet of Koytash is built (shown in Figure 2), 

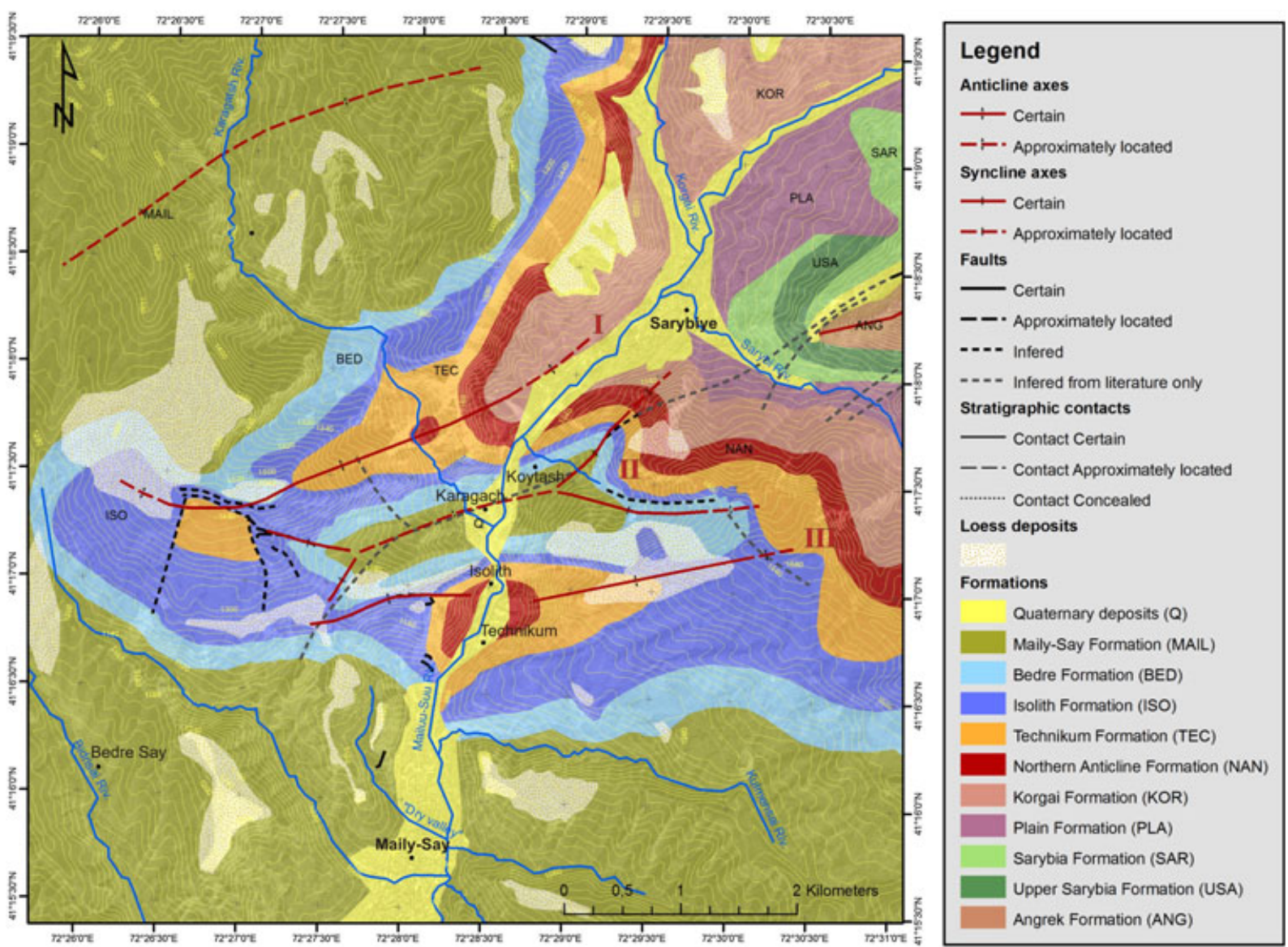

Figure 3. Geological map of Maily-Say Valley; I is the northern anticline; II the central syncline; and III the central anticline (axes marked in red). Loess deposits are marked by semi-transparent white dotted zones. This figure is available in colour online at wileyonlinelibrary.com/journal/espl

and several other large mass movements in the Maily-Say region can only be partly outlined along their head-scarps.

The horizontal area of each landslide (polygon) has been calculated in order to study statistically the evolution of the landslide distribution in the region.

\section{NDVI subtraction to detect landslides}

The spectral signature of a new landslide is usually an expression of soil or rock (Chang and Liu, 2004) it generally appears as a distinct bright feature on panchromatic images (Rosin and Hervas, 2002). The NDVI, initially developed for classification of vegetation type and health, is here applied to detect fresh translational mass movements such as debris flows and earth flows, which are quite common in Maily-Say valley. It is calculated on the basis of the red and near-infrared bands, which depend strongly on the presence of vegetation, according to the following equation:

$$
N D V I=(N I R-R) /(N I R+R)
$$

This processing allows for improved differentiation between spectrally different surfaces, compared with the use of one band only. Further, band ratioing greatly mitigates shadow effects that sometimes make visual interpretation difficult. The values of this index, also an indicator of biomass, are in the range between -1 and 1 ; negative values indicate bare lands and positive values indicate a greater level of photosynthetic activity due to the presence of vegetation (often included between 0.2 and 0.8). Barlow et al. (2003), studying landslides of another area based on NDVI, considered a value of 0.69 as threshold for indicating vegetative recolonization. In arid regions like Tien Shan, the spectral signature of recolonizing vegetation is very different because of the species, especially grassed and low shrubs.

Image differencing, or subtraction, is based on a pair of co-registered raw or transformed images of the same area collected at different times. The process simply subtracts pixel values on a pixel-by-pixel basis to generate a third image composed of numerical differences between the pairs of pixels (Ridd and Liu, 1998). Threshold boundaries between changing and stable pixels were determined to produce a change map (Song et al., 2001). These threshold values indicate whether large or major changes have occurred (Teng et al., 2008).

One interesting application of this method is to apply it to images acquired before and after landslide events in order to identify landslides according to their NDVI value (Lin et al., 2005; Teng et al., 2008). In this study, we analysed where new landsides appeared or old ones were reactivated between 2002 and 2007. Eleven classes with seven negative classes give the most representative results to recognize new landslides. The process leading to a new image, using the available Quickbird satellite images of these two periods, can be quantified by the following equation (here applied to the b-band of the images):

$$
D x_{i j}^{b}=x_{i j}^{b}\left(t_{2007}\right)-x_{i j}^{b}\left(t_{2002}\right)
$$

where $\mathrm{x}^{\mathrm{b}}{ }_{\mathrm{ij}}\left(\mathrm{t}_{2007}\right)$ and $\mathrm{x}^{\mathrm{b}}{ }_{\mathrm{ij}}\left(\mathrm{t}_{2002}\right)$ are the digital numbers (DNs) of a pixel $(i, j)$ of b-band for the 2007 and 2002 images, respectively. 
In the new image $\left(D x^{b}{ }_{i j}\right)$, positive or negative values denote the region whose radiation value has increased or decreased, respectively, between 2002 and 2007; a 0-value corresponds to no change in the region.

An important parameter that decides the capability of change detection is the choice of the threshold digital value. The changed and unchanged regions will be determined by this selection. A suitable threshold value allows us to distinguish the areas of 'real' changes from those marked by the impact of random factors (Shaoqing and Lu, 2008). If a high threshold value is selected, many 'real' changes would not be detected, while a low threshold value would produce many 'artificial' changes.

In the frame of this study, the NDVI images are chosen as the feature images for differencing because the difference between NDVI of multi-date images should give a reasonable indication of change in the vegetation canopy due to the disrupted vegetation triggered by new landslides. The pre- and post-NDVI images have been created following the equation: $\Delta \mathrm{NDVI}=\mathrm{NDVI}_{2007}-\mathrm{NDVI}_{2002}$.

\section{Results}

\section{Geological influence}

The northern slopes of the Maily-Say Valley are mainly made up of Paleozoic rocks while the foothills in the south are formed by Tertiary sedimentary rocks; along the valley
Quaternary terraces are dipping southward to the Fergana Basin (Figures 3 and 4). The central part of the valley hosting the town of Maily-Say shows a series of folds. The cores of the open anticlines (fold angle of about $100^{\circ}$ ) are made of soft siltstone and sandstone (Cretaceous rocks) overlain by alternating Paleogene to Neogene claystone and limestone (Figure 3). The central anticline has an east-west oriented fold-axis plunging to the west while the fold-axis of the central syncline has an orientation changing from east-west to north-east-south-west.

On the basis of a new geological map (Figure 3), the slope instability distribution in the Maily-Say Valley was compared with the geologic setting (Figure 4(a)). Figure 4(b) shows the susceptibility of each geological formation to slope instability in terms of landslide density per geological unit (ratio between landslide area and formation area, estimated for the 2007inventory). The graph indicates that the highest landslide density is observed for the Bedre Formation made of Paleogene claystone. The directly underlying Isolith Formation made of Paleogene limestone is the second most susceptible formation to landsliding. Field observations confirmed that landslides are generally located within soft sediments composed of clay material or loess (Figure 3) overlying the limestone layers. Fieldwork revealed that many slope instabilities have their head-scarps in the Isolith limestone layers. This means that they were initiated there, but affected mostly material of the adjacent units.

Landslide occurrence also spatially correlates with structural and morphological factors, such as strike-and-dip of the limestone layers, the slope aspect, slope angle, and curvature.

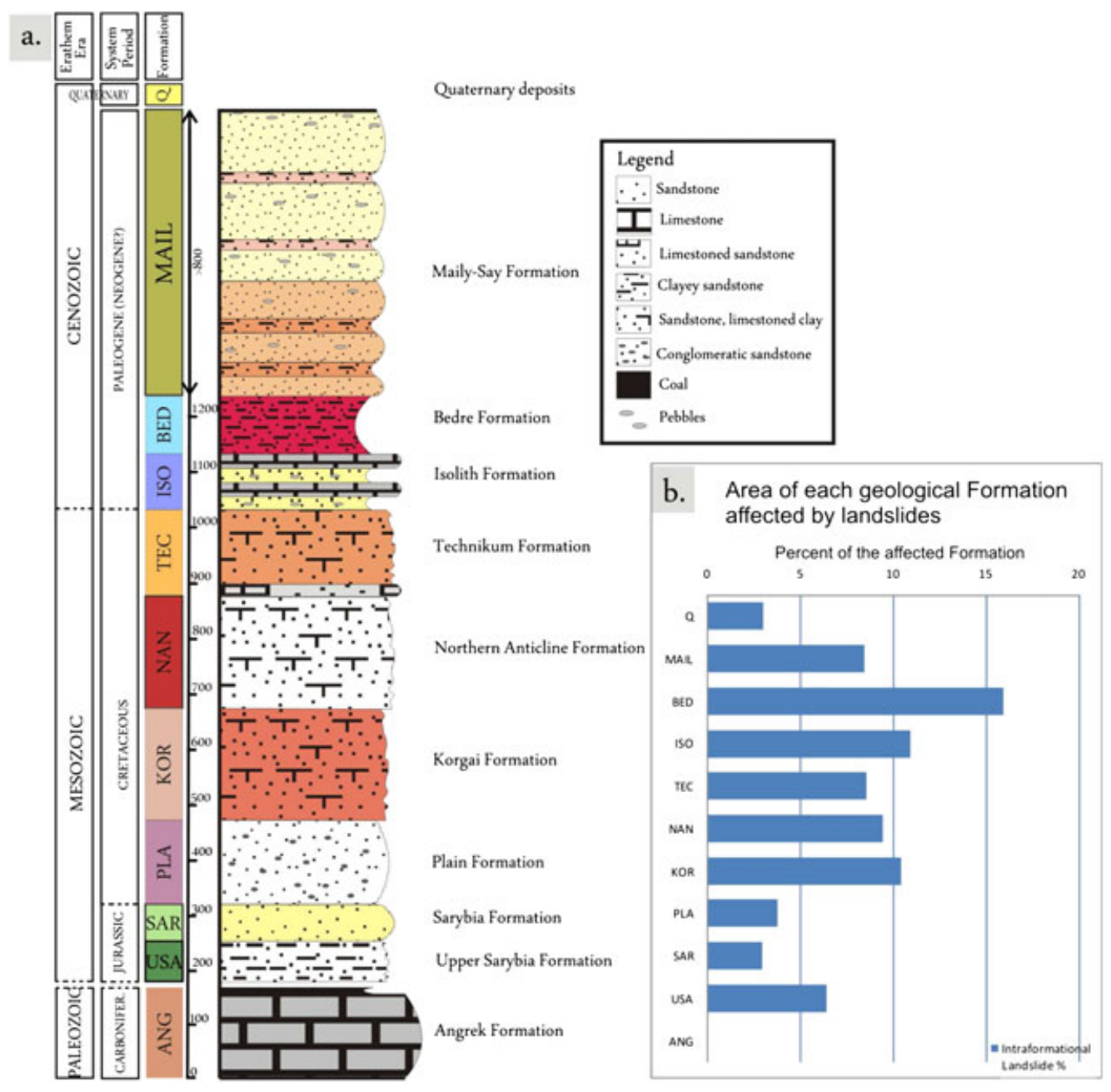

Figure 4. (a) Litho-stratigraphic column of the rocks and deposits mapped in the Maily-Say Valley; (b) graph showing the density of slope instabilities (of 2007 inventory) within each geological formation. This figure is available in colour online at wileyonlinelibrary.com/journal/espl 
Related results based on spatial analysis applied to rasters (for structures of $50 \mathrm{~m}$-distance buffers) are not discussed here since these correlations are part of an ongoing landslide susceptibility analysis.

\section{Evolution of landslides at regional scale}

The landscape in the Maily-Say Valley is continuously changing owing to the high landslide activity. The extent of this potentially dangerous evolution was quantified statistically (Figure 5). The total area affected by landslides increased from $1.0 \%\left(\sim 1.2 \mathrm{~km}^{2}\right)$ in 1962 to $3.3 \%$ in $1984,4.5 \%$ in $1996,4.3 \%$ in 2002 and $5.6 \%\left(\sim 6.5 \mathrm{~km}^{2}\right)$ in 2007, compared with the entire area investigated along the Maily-Say Valley (Figure 5(a)). The slight decrease of $0.2 \%$ from 1996 to 2002 is probably related to the changed dataset used for mapping (aerial photographs and existing inventories in 1996 and before, Quickbird imagery for 2002 and 2007). The mean landslide size increased from $15,170 \mathrm{~m}^{2}$ in 1962 to $31,000 \mathrm{~m}^{2}$ in 2007 . Landslide size is quite variable; it ranges from $335 \mathrm{~m}^{2}$ for the smallest detected landslide to $348425 \mathrm{~m}^{2}$ for the largest one in 2007. The evolution of the formation of the largest mass movement (Figure $5(b)$ ) is marked by the formation of landslide Tektonik in 1992. As a result, the maximum landslide size increased from $110,000 \mathrm{~m}^{2}$ in 1984 to $325,000 \mathrm{~m}^{2}$ in 1996 .

Digitized landslides from all five inventories have been divided into four size-classes: less than $10,000 \mathrm{~m}^{2}$ (small), between 10,000 and 25,000 $\mathrm{m}^{2}$ (medium), between 25,000 and $100,000 \mathrm{~m}^{2}$ (large) and more than $100,000 \mathrm{~m}^{2}$ (very large).
The graph in Figure 5(c) shows that for all inventories, small landslides are more frequent than larger ones. Further, the results indicate that the absolute number of large and very large landslides increases over time while the absolute number of small landslides decreases. The latter observation can partly be explained by the incompleteness of the most recent inventories: some small and older landslides mapped by previous workers are no longer visible on the recent images and the fieldwork of the present study did not cover the entire area. However, this would only apply to the first class since it can reasonably be assumed, considering the high resolution of the images and consideration of local field observations, that all our inventories are complete for landslides larger than $10,000 \mathrm{~m}^{2}(100 \times 100 \mathrm{~m}$ corresponding to about $40 \times 40$ pixels on multi-spectral Quickbird images).

\section{Size-frequency distribution of landslides}

In order to further characterize the landslide activity, sizefrequency relationships were computed for the two new datasets of 2002 and 2007 counting 189 and 208 records, respectively, and for three older landslide inventories of the same area from 1962, 1984, and 1996 (modified/corrected from the 1962 and 1977 maps presented by Havenith et al., 2006; Figure 6).

The frequency-area distribution quantifies the number of landslides per class of surface area. Following the method of Malamud et al. (2004), the size-frequency relationships of these five datasets were analysed in terms of the frequency
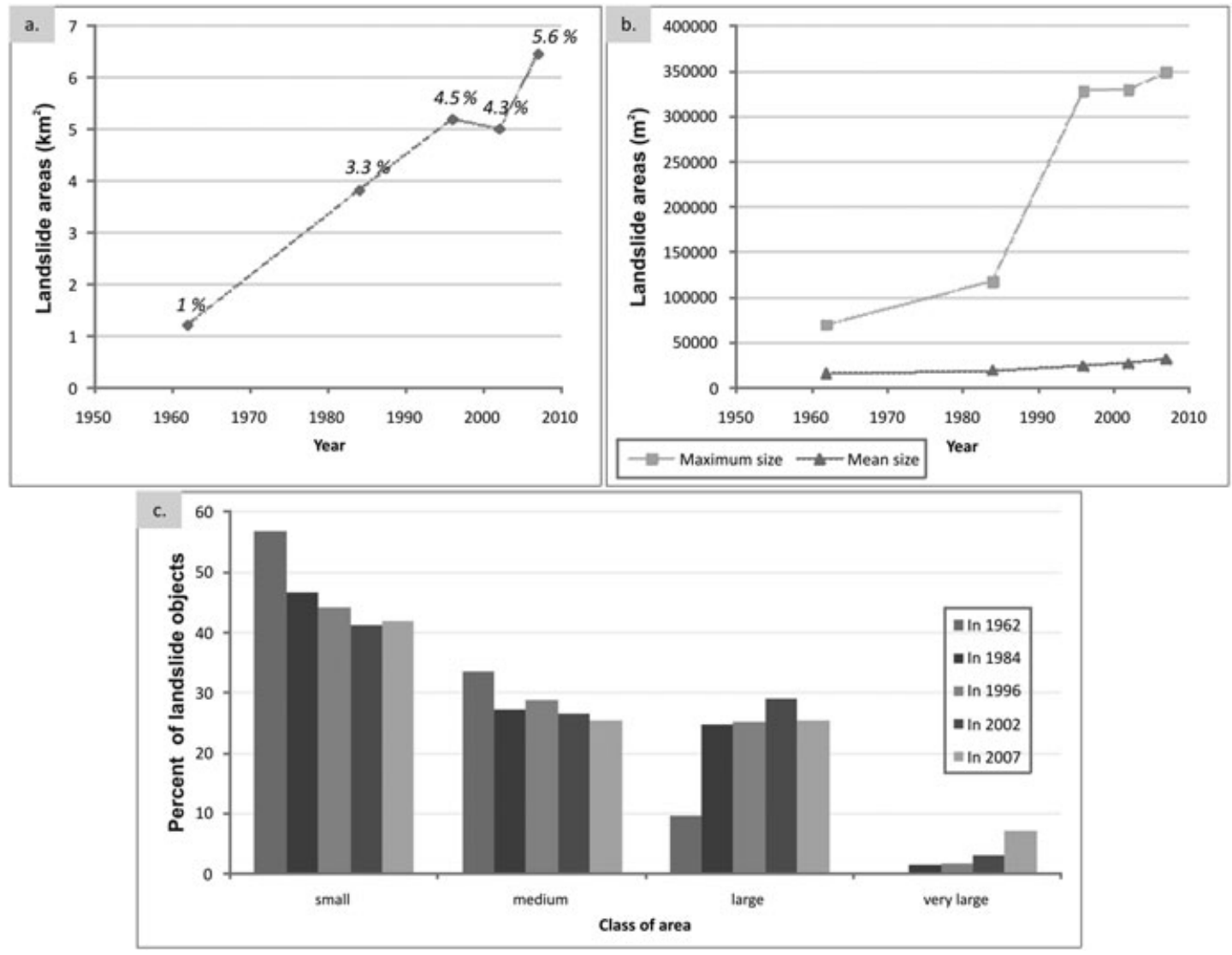

Figure 5. Summary of landslide extent in the Maily-Say Valley from inventories by year. (a) Portion of inventory area affected by landslides in $\mathrm{km}^{2}$ affecting the Maily-Say Valley slopes from 1962 to 2007 (the percentage with respect to the entire area has been added to the symbol). (b) Evolution of the maximum and mean landslide sizes (in $\mathrm{m}^{2}$ ) affecting the slopes (note the important increase of maximum landslide size from 1984 to 1996 due to the formation of landslide Tektonik in 1992). (c) Proportion of landslide events by size class for each inventory (in \% compared with the total number of landslides of each inventory). The total surface is around $115.4 \mathrm{~km} 2$. 


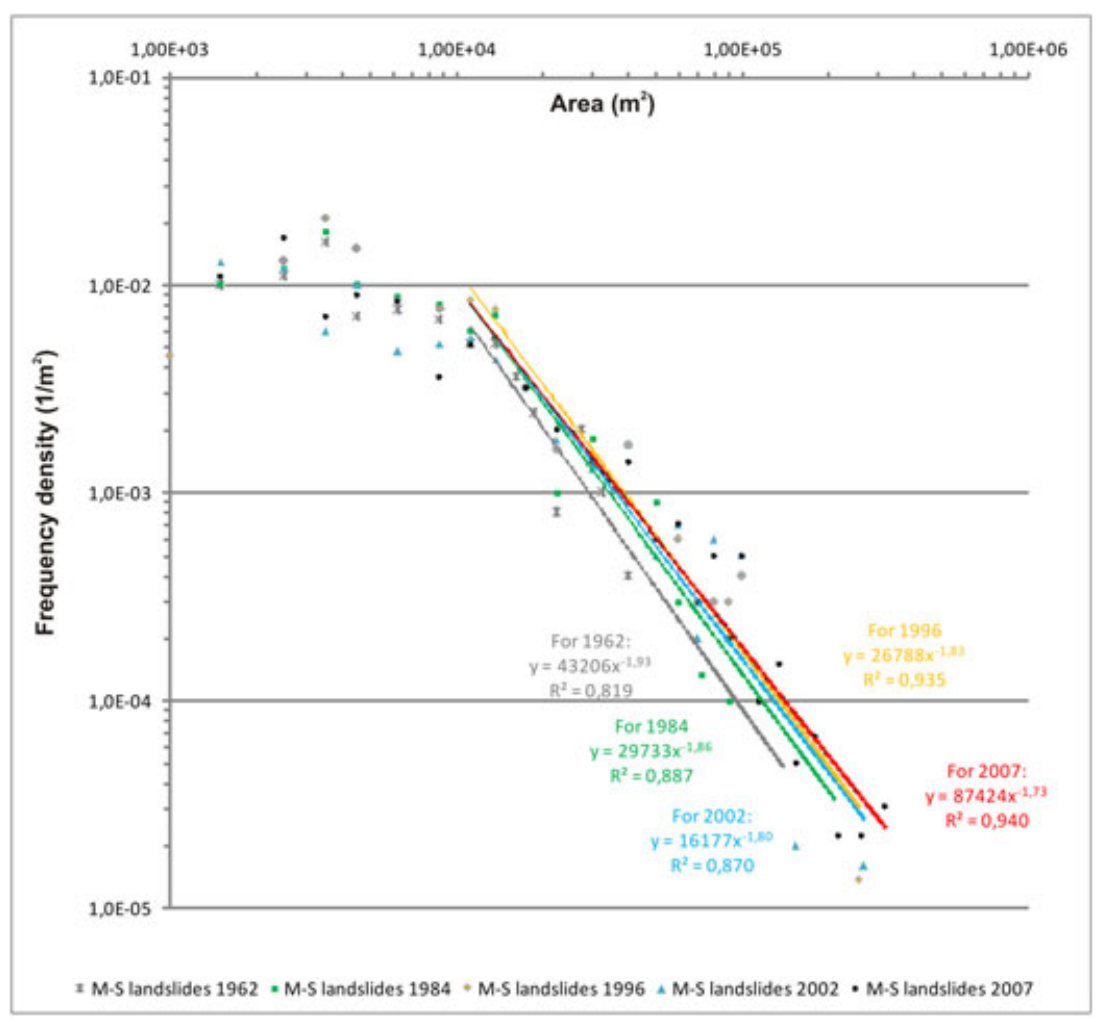

Figure 6. Frequency density function for landslide areas in the Maily-Say Valley in 1962 (162 objects), 1984 (206 objects), 1996 (222 objects), 2002 (189 objects), and 2007 (208 objects). This figure is available in colour online at wileyonlinelibrary.com/journal/espl

density function $(f)$ of the landslide areas $\left(A_{L}\right)$ using the following equation:

$$
f\left(A_{L}\right)=\delta N_{L} / \delta A_{L}
$$

where $\delta N_{L}$ is the number of landslides with areas between $A_{L}$ and $A_{L}+\delta A_{L} \cdot \delta A_{L}$ is the width of the respective area class. In a log-log graph (Figure 6), this function shows the typical behaviour of records of naturally occurring phenomena (e.g. earthquakes, landslide events in terms of activations) and objects (e.g. faults, fractures, geomorphologic features) characterized by a more-or-less linear tail (in log-log graph) which can be fitted by a power law (Turcotte, 1997). A rollover (inflection) is observed for smaller events and objects, here represented by the decreasing frequency density for very small landslide areas (Malamud et al., 2004; Havenith et al., 2006). The deviation from the power-law trend on the left part of the graph is partly explained by undercounting of the small landslides, which could be taken into consideration by particular distribution fits (Stark and Hovius, 2001). As discussed by Malamud et al. (2004), many factors cause the incompleteness, such as the quality of imagery, landslide age and freshness, the potential removal of geomorphologic and spectral properties, the experience of the scientist involved. Pelletier et al. (1997) attributed the rollover shown by the probability density function of landslide areas, to a transition from a resistance controlled chiefly by friction (for large landslides) to a resistance controlled by cohesion (for small landslides).

Here, only the linear trend of the size-frequency relationships (e.g. for a size greater than the rollover, which is roughly $10,000 \mathrm{~m}^{2}$ ) of the five inventories has been considered. This confirms the probable completeness of all the inventories above that threshold. The fits of these linear tails of a complete relationship by a power law are characterized by coefficients of determination, $\mathrm{R}^{2}$, larger than 0.8 .
From the size-frequency analysis presented in Figure 6, it can be seen that the trends slightly but constantly change over time. The related exponent values continuously decrease from 1.93 in 1962 to 1.73 in 2007. The value obtained for the 2002 dataset, 1.8, is similar to the power-law exponent determined by Havenith et al. (2006) for Maily-Say landslide records obtained from field observations in 2003, which is equal to 1.9. This confirms the observed trend indicating the more frequent formation of large landslides (in terms of objects and not in terms of events or movements) in the region. The increasing frequency of large landslides can be related to the growth of existing landslides or the coalescence of smaller landslides, as already suggested by Havenith et al. (2006). The latter process probably also contributes to the fact that the number of small landslides is decreasing over time (as shown also in Figure 5(c)).

\section{Evolution of selected landslides}

The highest landslide risk in the study area is posed by the Koytash, Tektonik and Isolith landslides, which are concentrated in the area of the central anticline close to Karagach village and the upper part of the town of Maily-Say (Figure 2). The evolution of these and the surrounding landslides is shown in Figure 7 on the basis of a comparison between aerial photographs of 1984 and 1996 and the satellite images of 2002 and 2007. Here, focus will be on the evolution of the Tektonik landslide and the Upper-Koytash earth flow located $150 \mathrm{~m}$ in the north.

\section{Tektonik landslide}

The present main scarp of the Tektonik landslide formed during 2000 about $100 \mathrm{~m}$ behind the former main scarp, which has now become a secondary scarp. The height of the new 


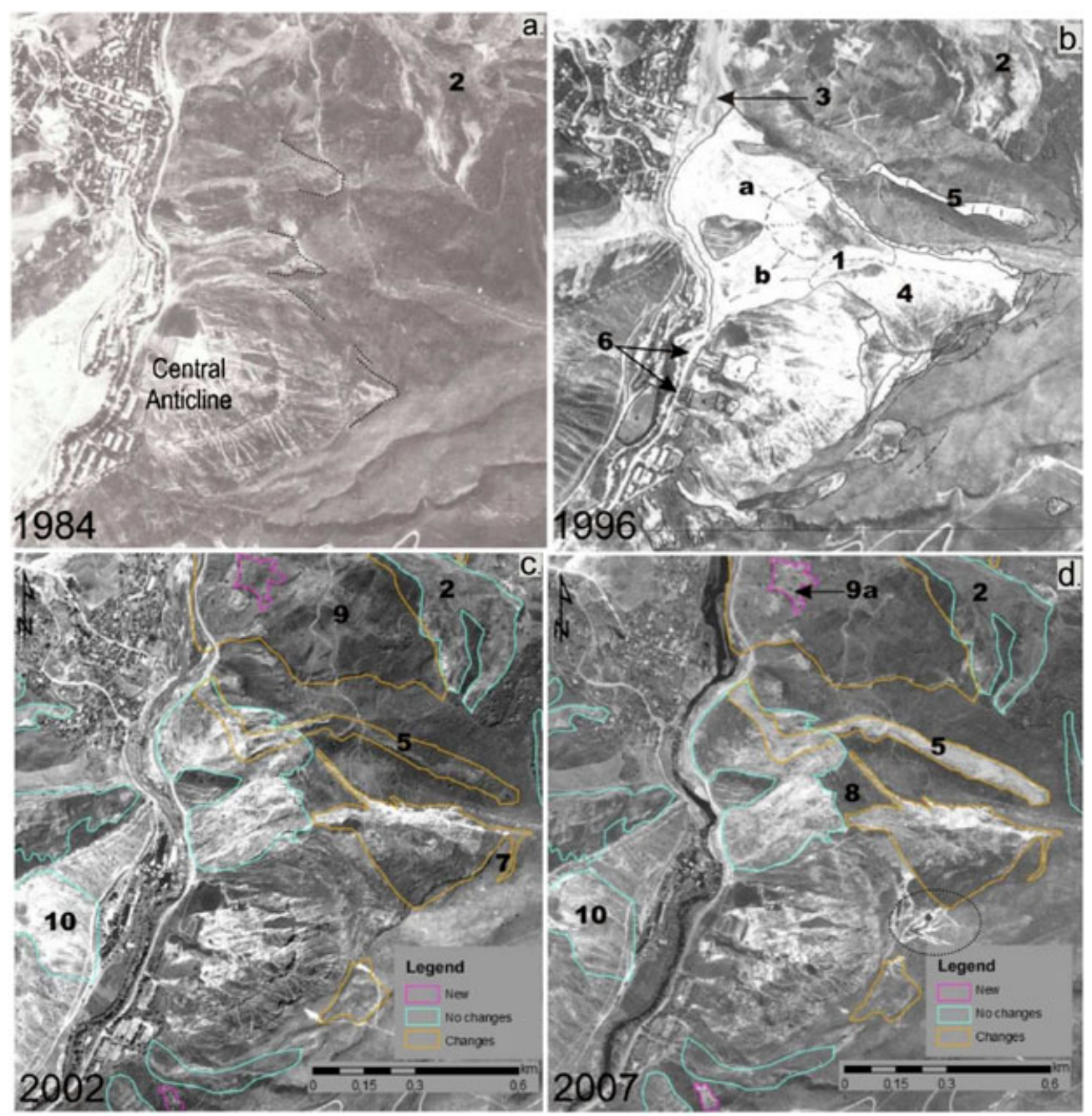

Figure 7. Aerial photographs (1984-1996, a,b) where particular unstable morphology was outlined by previous scientists as well as high resolution Quickbird images (2002-2007, c,d) of the Tektonik (1), Upper-Tektonik (4) and Upper-Koytash (5) landslides at different periods indicating the sliding activity. Additional points 2, 7, 8, 9, and 10 mark instability features explained in the text; point 3 shows the flooded area behind the Tektonik dam formed in 1992 and 1996; point 6 indicates the location of two nuclear waste tailings. Excavation works close to the scarp of Tektonik landslide are marked by a dotted ellipse close to the legend in (d). This figure is available in colour online at wileyonlinelibrary.com/journal/espl

head-scarp has increased from $4 \mathrm{~m}$ in 2004 to $16 \mathrm{~m}$ in 2008 (Figure 8).

From the 1984 photograph (Figure 7(a)) only a few small slope failures can be observed in the vicinity of the central anticline. The 1996 photograph (Figure 7(b)) clearly shows that new landslides and earth flows developed after 1984. Tektonik is the largest slope failure of the valley $\left(n^{\circ} 1\right.$, Figure 7 (b)), situated $1.5 \mathrm{~km}$ upstream of Maily-Say town, which was strongly activated a few weeks after the 15 May 1992, earthquake; only a few signs of instability could be observed earlier in a small area, see black dotted lines in Figure 7 (a). The landslide in the north $\left(n^{\circ} 2\right.$; Figure $\left.7(a)\right)$ existed in 1984. Between 1984 and 1996, the riverbed changed; it became wider than before, especially upstream from Tektonik landslide, which had dammed the river in 1992 and 1996 (n³; Figure 7(b)). The Tektonik landslide developed into a slump marked by the presence of a series of fractures $\left(n^{\circ} 4\right.$; Figure $\left.7(b)\right)$, and into two main translational flow slides downslope (points a and b; Figure $7(b)$ ). It should be noticed that two nuclear waste tailings (highlighted by the drawing, $n^{\circ} 6$ in Figure $\left.7(b)\right)$ are directly exposed to landslides of this area.

The upper part of the main Tektonik landslide $\left(n^{\circ} 7\right.$, Figure 7 (c) and Figure 8 ) is also affected by new flows and growing fractures. Excavation works have been carried out since 2004 to stabilize the southern upper part of Tektonik (see removal of rocks marked by the dotted line above the 2007 image's legend in Figure $7(d)$ ).

\section{Upper-Koytash landslide}

One individual narrow flow occurred between 1984 and 1996 in the north of the Tektonik landslide. Disregarding the different degree of exposure of soil/bedrock on landslide surfaces between image dates, it can be seen that in 2002, this narrow flow ( ${ }^{\circ} 5$ in Figure $7(b)$, (c)) seems to have stabilized; its spectral difference from surrounding vegetated ground reducing over time. The 2007 Quickbird image (Figure 7(d)) shows a new reactivation of the Upper-Koytash earth flow $\left(n^{\circ} 5\right)$ (see also the earthflow in the middle part of the photograph in Figure 8 (a)). This small failure of 1996 turned into a 1-km-long earth flow in 2005.

\section{Koytash landslide}

The largest landslide (in terms of volume) in this area $\left(n^{\circ} 9\right.$, Figure $7(\mathrm{c})$ ), the Koytash landslide, is difficult to identify from the images alone. This is due to its rotational motion (described below). The activity of the Koytash landslide is only marked by a small and surficial slope instability, which developed between 2002 and 2007 ( $n^{\circ}$ 9a, Figure 7(d)).

On the other bank of the river, some mass movements are also active, including the Isolith landslide $\left(n^{\circ} 10\right)$, which will be described below. 

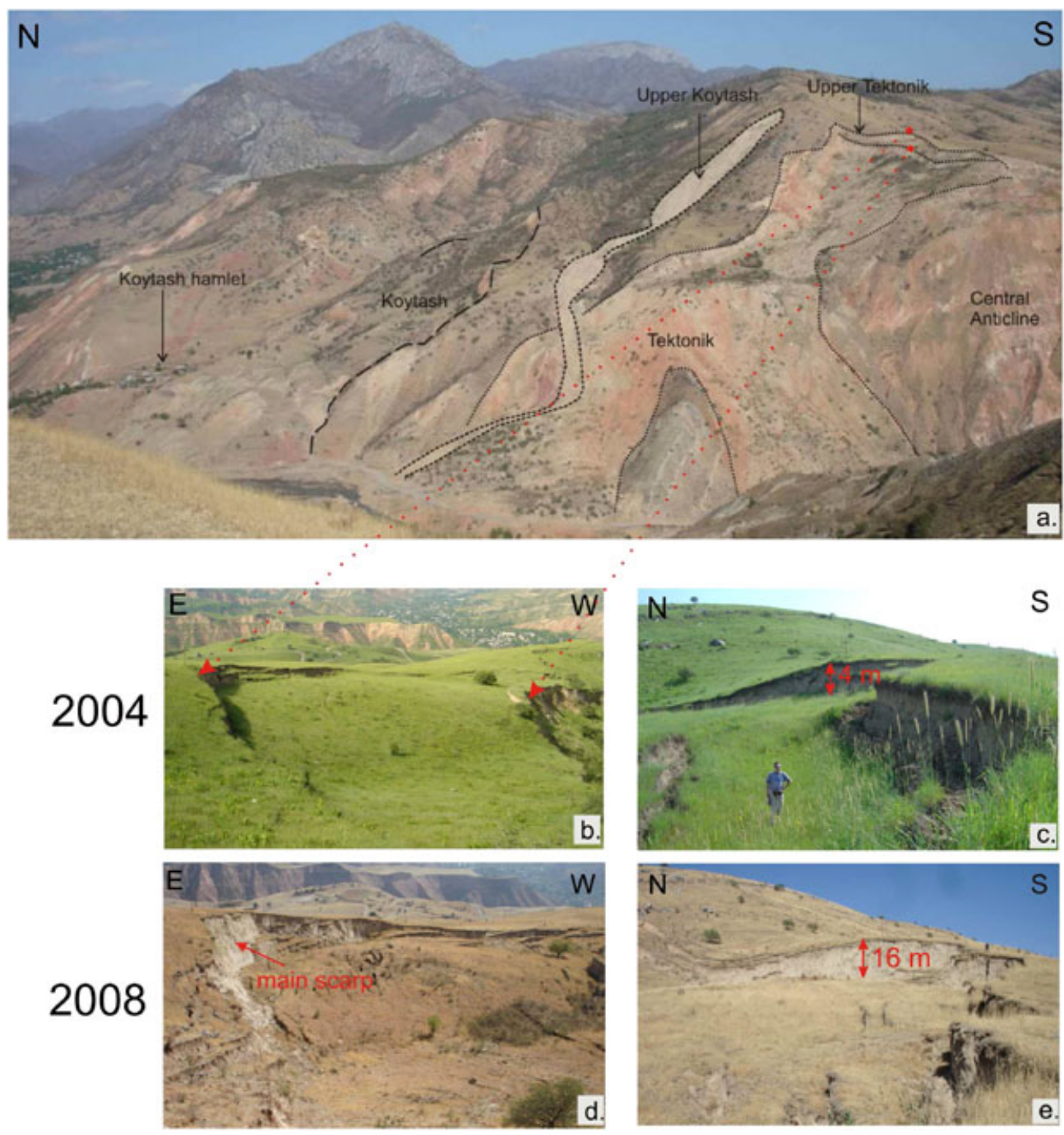

Figure 8. Evolution of landslide activity along the eastern slopes of the Maily-Say Valley (a) and the formation of the new head-scarp of the Tektonik landslide between 2004 (b and c) and 2008 (d and e). This figure is available in colour online at wileyonlinelibrary.com/journal/espl

\section{Application of NDVI subtraction}

NDVI change values

The results of the NDVI calculation for the 2007 Quickbird image show that values close to zero (see Figure 9(a) in Bedre Coupola) represent landslides partly denudated or sites covered by sparse vegetation. The histogram analysis of the NDVI map of the entire zone shows (Figure 9(a)) that, the average NDVI is lower in 2007 (NDVI of 0.26) than in 2002 (NDVI of 0.32). This difference may be due in part to the increasing landslide activity and to minor differences in vegetation growth stage. The mass movements in Figure 9 are generally complex combining deep-seated deformation with surficial erosion. Stable bare soil may be misclassified as landslides (see dotted ellipse in Figure 9(a)). Figure 9(b) shows clearly that the spectral signature of the 2007 Quickbird image computed with the ENVI software is very different for landslide (0.05) and stable slope (0.36).

The NDVI 2007-2002 subtraction maps of two zones are shown in the Figures 10 and 11. In general, most of the clusters of red pixels (marking a strong decrease of NDVI) seen all over these two scenes could be attributed to the loss of vegetation due to recent activation of landslides. However, a simple correlation between the decrease of vegetation and the presence of a landslide cannot be established. Each landslide has particular characteristics due to its type of movement (fall, topple, slide, slump, spread or flow) and its type of material (rock, debris, earth material). In addition, the age of a landslide must be considered. With this method, primarily, fresh earth flows can be detected.

By visual analysis, it seems that new activations are represented by the classes 7 to 10, i.e. by the NDVI change values of -0.1 to -0.5 (see in Figure 9(b) the decrease of the NDVI inside the activated landslide zone marked by the black square in Figure 9(a) from 0.3 in 2002 to 0.05 in 2007, i.e. a change of -0.25$)$.

A statistical analysis shows that $88 \%$ of the landslide areas are marked by NDVI change values of 0.0 to -0.5 . However, only $27 \%$ of the pixels inside the landslides belong to the NDVI change values of -0.1 to -0.5 . This shows that only parts of the landslides can be clearly detected by the method.

\section{Central part of the valley}

The central part of Maily-Say Valley, which contains the Tektonik and Koytash landslides, is continuously changing. The NDVI subtraction method helps detect recently activated landslides, such as the Upper-Koytash earth flow (Figure 10). Another irregular fresh flow can be seen in the northern part of the map $\left(\mathrm{n}^{\circ} 2\right.$; Figure $\left.10(\mathrm{c})\right)$. However, some landslides cannot be well identified by this method, such as the large, deep-seated rotational Koytash landslide (Figure 8), 


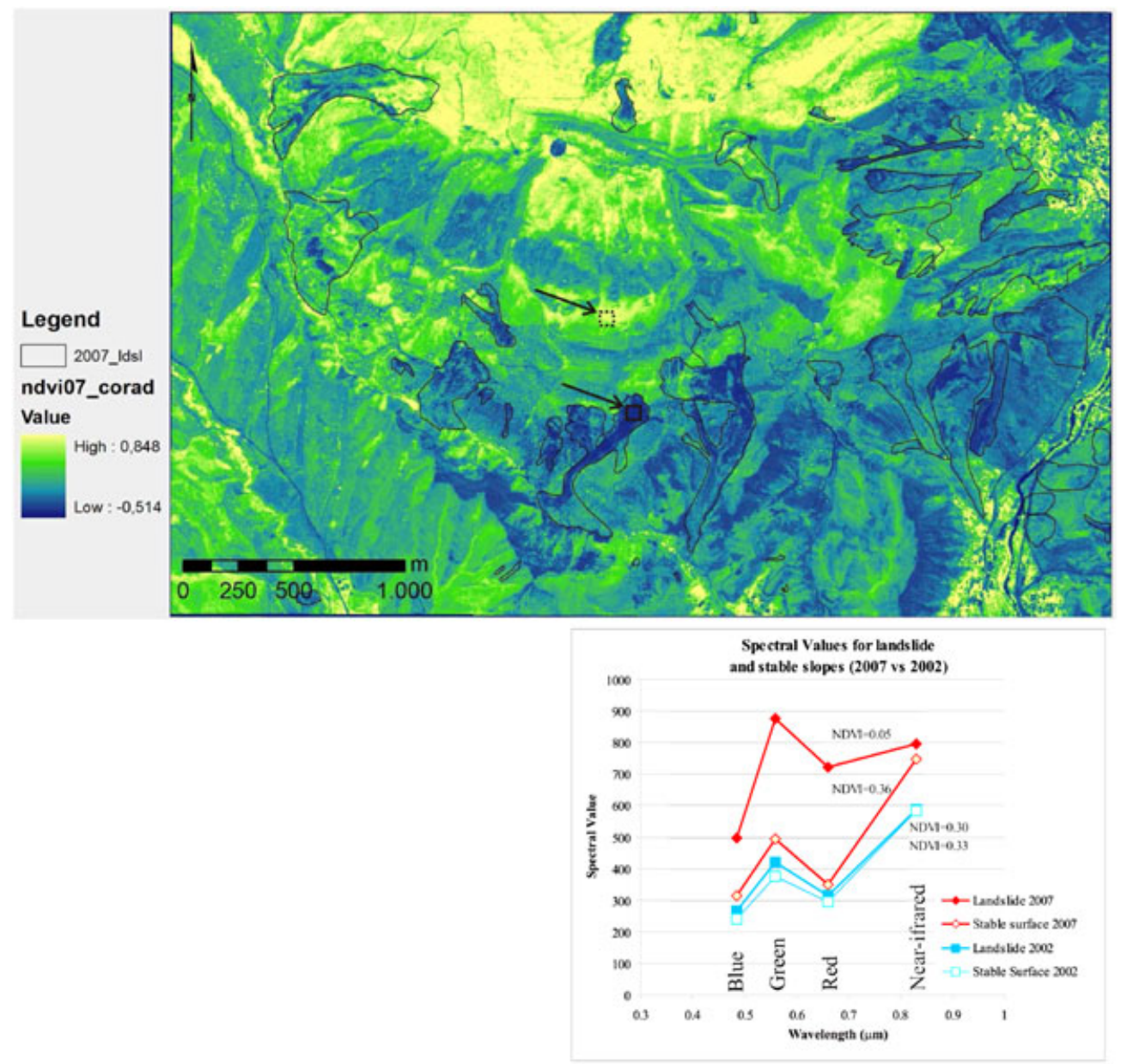

Figure 9. (a) NDVI of the radiometrically corrected 2007 Quickbird image of the Bedre Coupola area where bluish colours represent low NDVI and greenish to yellow colours represent high NDVI, and the 2007 landslide inventory for the zone (see also an example of denudation processes with low NDVI outlined by a dashed ellipse). (b) Spectral values for landslide sites (computed from the black square of $60 \times 60 \mathrm{~m}$ in the middle lower part of the map) and stable slope (dotted square in the middle part), with respective NDVI values for the 2007 image, compared with spectral values and NDVI for corresponding areas in the 2002 image. This figure is available in colour online at wileyonlinelibrary.com/journal/espl

which is moving slowly (several centimetres per year). Only surficial movements within the landslide can be detected $\left(n^{\circ} 3\right.$, Figure 10(c)).

Western part of the valley (Bedre Coupola)

The Big Bedre landslide $\left(\mathrm{n}^{\circ} 1\right.$ in the eastern part of Figure 11) exemplifies detection and evaluation of landslide reactivations between 2002 and 2007. Its upper unstable part is mainly marked by high classes of NDVI change values $\left(\mathrm{n}^{\circ} 1 \mathrm{a}\right.$, Figure 11 (c)); it corresponds to a slumping part. Formation of a large landslide by the coalescence of initially independent flows is illustrated by the circle $\mathrm{n}^{\circ} 1 \mathrm{c}$, Figure 11(c). From these observations it can be inferred that almost the entire mass movement has changed from 2002 to 2007.

The Medium Bedre landslide $\left(\mathrm{n}^{\circ} 2\right.$, Figure $\left.11(\mathrm{c})\right)$ has been clearly reactivated (class 6 to 11 ) in the eastern upper part and close to its toe $\left(\mathrm{n}^{\circ} 2 \mathrm{e}\right)$. It is, however, difficult to detect the link between those two zones reactivated between 2002 and 2007 because the path of the new flow $(\mathrm{s}), \mathrm{n}^{\circ} 2 \mathrm{~d}$, cannot be reliably detected (between class 6 and 11).

\section{Discussion and Conclusion}

The Maily-Say Valley can be considered a geological and environmental hazards hotspot within the Tien Shan Mountains (Blacksmith Institute, 2006). Disasters producing social and economic losses occur almost every year. All statistics of the evolution of landslides indicate that the hazard is likely to increase. Size-frequency analyses have been applied to five landslide datasets of 1962, 1984, 1996, 2002 and 2007. A major issue related to these analyses applied to the inventories is the completeness of the catalogue. We consider that all catalogues are complete for landslides larger than $10,000 \mathrm{~m}^{2}$. Above this threshold, all size-frequency relationships show a linear tail that can be fitted by a power law. The exponent values of the respective power-law fits continuously decrease from 1.93 in 1962 to 1.73 in 2007 . This reveals a trend towards the formation of increasingly larger landslides on the Maily-Say slopes.

The size-frequency behaviour of the landslides in Maily-Say can be compared with some observations made by other researchers concerning landslide distributions. All exponent values obtained for the five inventories are well below those calculated by several other researchers, e.g. by Stark and Hovius (2001) and Malamud et al. (2004) studying landslide inventories of landslide types and distributions as well (the values are between 2.11 and 2.48). However, the exponent values of the five inventories presented here compare well with those calculated by Chen (2009) for the landslides triggered by the 1999 Chi-Chi earthquake (value of 1.8). He noted that the exponent value increased for post-seismic landslides triggered by Typhoons in 2001 and 2004 (values of 2 to 2.1). This change of the exponent values of about 0.2-0.3, considered significant by Chen (2009), is similar to the one observed for the Maily-Say landslides. 

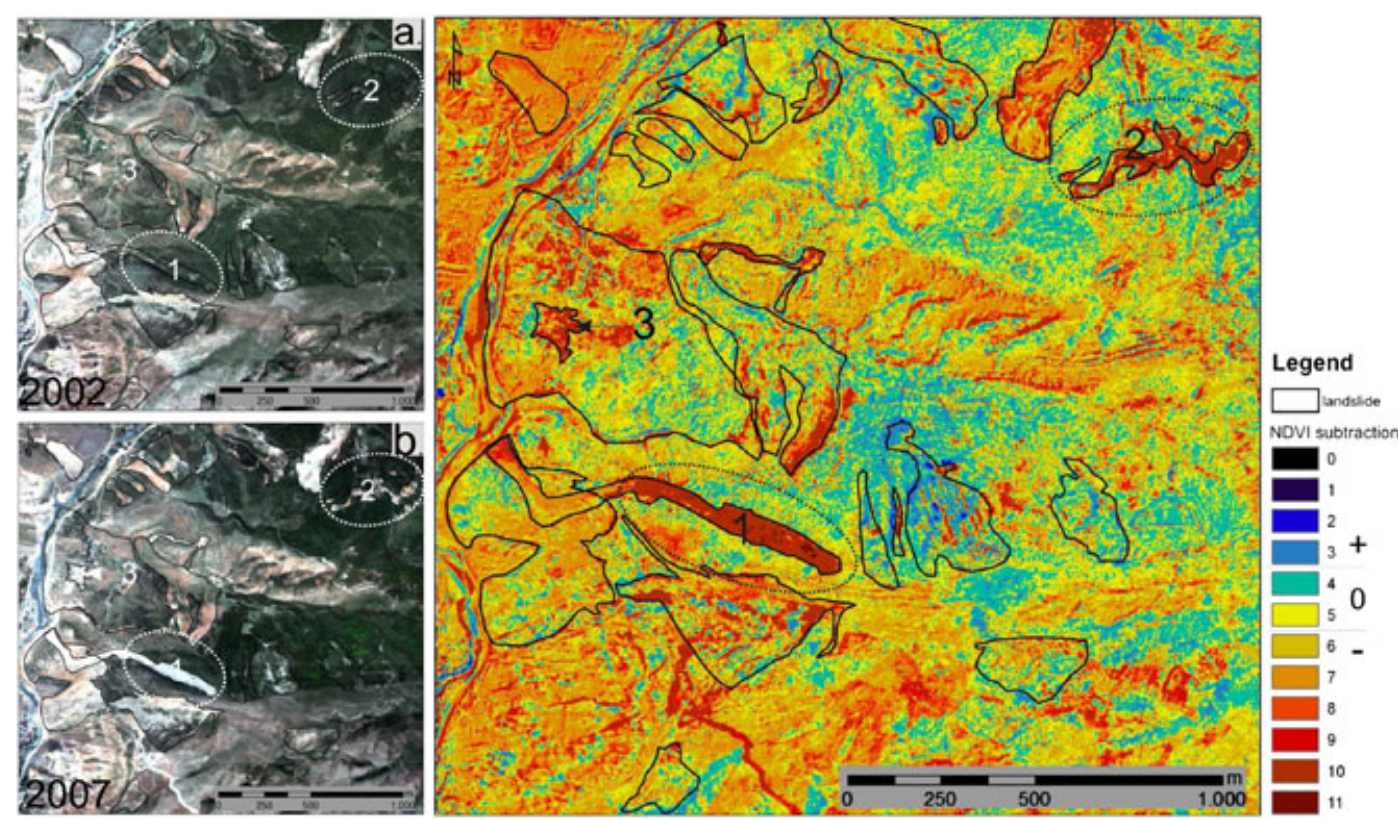

Figure 10. View of the landslides of the main Maily-Say Valley (eastern riverbank) in 2002 (a) and 2007 (b) and the result of NDVI subtraction using 11 classes; Point 1 corresponds to the Upper-Koytash earth flow; Point 2 is a new irregular fresh flow, and Point 3 corresponds to a fresh flow within the rotational Koytash landslide. Legend shows that from class 7 (negative values), reactivated parts are detected. This figure is available in colour online at wileyonlinelibrary.com/journal/espl

Changes of landslide size-frequency statistics can be compared with those related to other geohazards processes. For instance, Amitrano et al. (2005) analysing the statistical pattern of seismicity before a cliff collapse, showed that the size-frequency relationship of microseismic shaking amplitudes changed over time before the rockfall. The exponent-value of the power-law fit continuously decreased until the collapse.

Here, we relate the continuous decrease in the exponent value of the landslide size-frequency distribution to the growth (exemplified in Figure 7) and coalescence of existing landslides (shown, for example, around the circle c in Figure 11(c)), which are relatively more frequent than the formation of new small slope instabilities. In this regard, it can be assumed that the changing size-frequency distribution of the landslide bodies in Maily-Say is related to the increasing density of slope instabilities. We think that a certain landslide density threshold has been surpassed, beyond which landslide occurrences become interdependent and are not only related to changing environmental conditions and external triggers. Furthermore, power-law exponent values decreasing over time could indicate
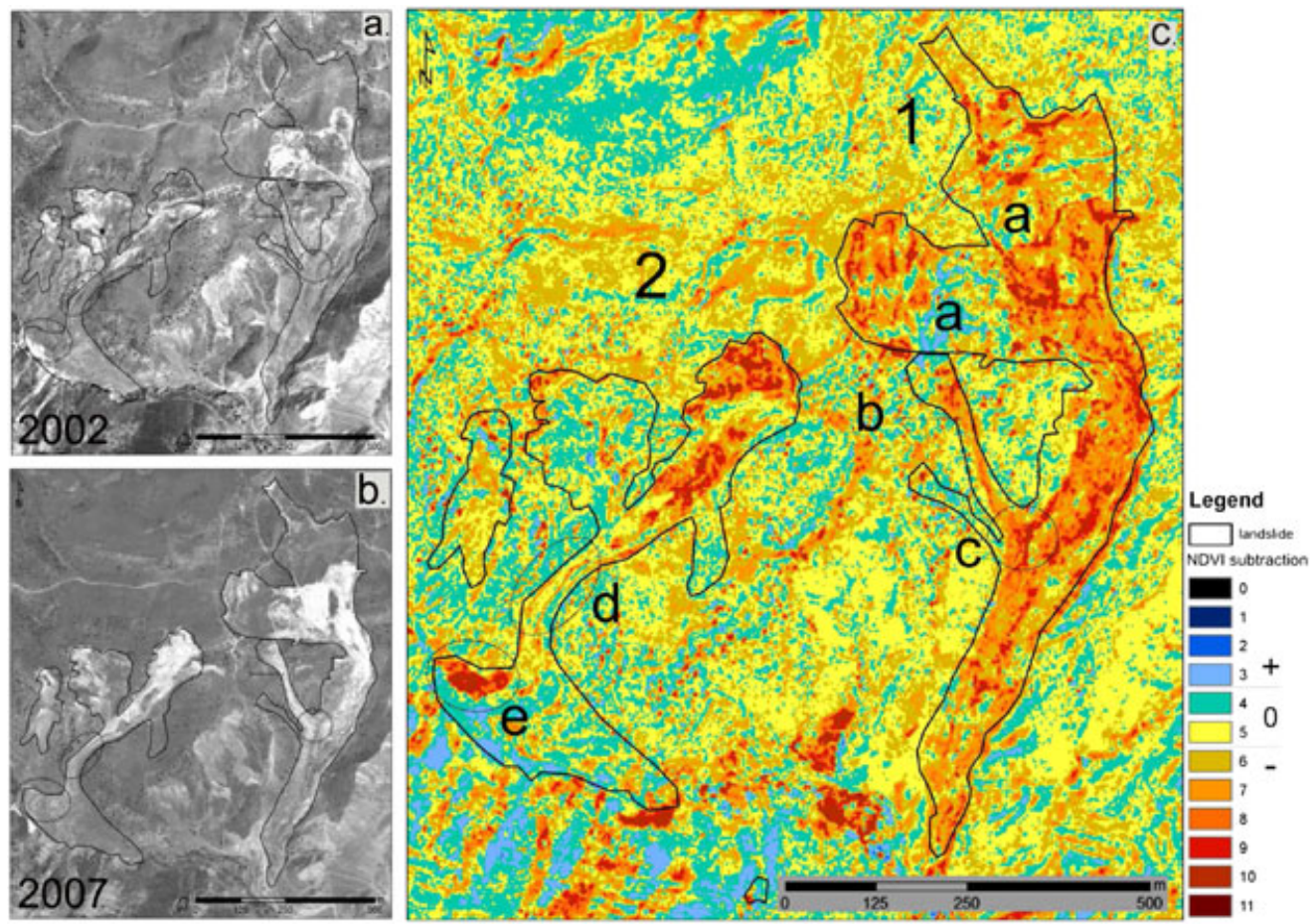

Figure 11. View of the Big ( $n^{\circ} 1$ to the east) and Medium ( ${ }^{\circ} 2$ to the west) Bedre landslides of the Bedre Cupola, west of Maily-Say (underlined in black) in 2002 (a) and 2007 (b), and the result of NDVI subtraction using 11 classes. Legend shows that from class 7 (negative values), reactivated parts are detected. This figure is available in colour online at wileyonlinelibrary.com/journal/espl 
a trend towards a cataclysmic situation (such as was shown by Wiemer and Schorlemmer, 2005, for the 2004 Parkfield earthquake and by Amitrano, 2005, for the cliff collapse) - here, this could mean that in the near future larger parts of slopes could fail catastrophically. However, to be able to confirm this, we will also quantitatively assess changes in the landslide sizes and continuously monitor landslide reactivations in hazardous places. Therefore, automatic detection methods are needed.

As many new landslides are translational and constituted by clay and loess deposits, a change detection method, based on image subtraction to detect (re)activations was developed. Differencing of NDVI values determined from the multispectral Quickbird images $\left(\mathrm{NDVI}_{2007}-\mathrm{NDVI}_{2002}\right.$ ) allowed us to outline zones with removed vegetation due to active slope failures considering inherent errors of commission in mapping. In addition, the recent landslide activity and increasing surface denudation are marked by a decrease in the average NDVI from 0.32 in 2002 to 0.26 in 2007 . This analysis allows us to demonstrate that the multi-temporal differencing method is quite useful to detect both (re)activations of landslides and stabilizing slopes (marked by re-vegetation). However, it is not well adapted to map landslides or to create an inventory of them. For that purpose, a uni-temporal method is more appropriate such as data mining, which is able to combine many different parameters influencing slope stability and/or affected by the presence of landslides (e.g. spectral bands, curvature, slope, roughness). The main advantage of this process is to quantify the importance of each measurable parameter and then, to valid and criticize the results considering manual geomorphic interpretation. Ongoing and future studies applied to this area focus on the reassessment of landslide susceptibility using data mining techniques.

Acknowledgements - These studies have been supported by the NATO Science for Peace Project 'Prevention of landslide dam disasters in the Tien Shan, LADATSHA'. We would like to thank two anonymous reviewers and the editor for their helpful comments.

\section{References}

Abdrakhmatov K, Havenith HB, Delvaux D, Jongmans D, Trefois P. 2003. Probabilistic PGA and arias intensity maps of Kyrgyzstan (Central Asia). Journal of Seismology 7: 203-220.

Amitrano D, Grasso JR, Senfaute G. 2005. Seismic precursory patterns before a cliff collapse and critical point phenomena. Geophysics Research Letters 32: L08314, DOI:10.1029/2004GL022270.

Barlow J, Martin Y, Franklin SE. 2003. Detecting translational landslide scars using segmentation of Landsat ETM+ and DEM data in the northern Cascade Mountains, British Columbia. Canadian Journal of Remote Sensing 29(4): 510-517.

Blacksmith Institute. 2006. The world's worst polluted places - the top ten. Blacksmith Institute, New York. http://www.blacksmithinstitute. org/top10/10worst2.pdf (April 16, 2009)

Brardinoni F, Slaymaker O, Hassan MA. 2003. Landslide inventory in rugged forested watershed: a comparison between air photo and field survey data. Geomorphology 54: 179-196.

Chang KT, Liu JK. 2004. Landslide features interpreted by neural network method using a high-resolution satellite image and digital topographic data. International Archives of Photogrammetry Remote Sensing and Spatial Information Science 35: 574-579.

Chen CY. 2009. Sedimentary impacts from landslides in the Tachia River Basin, Taiwan. Geomorphology 105: 355-365.

Du Y, Teillet PM, Cihlar J. 2002. Radiometric normalization of multitemporal high-resolution satellite images with quality control for land cover change detection. Remote Sensing of Environment 82: 123-134.

Gupta RP. 2003. Remote Sensing Geology, 2nd edn. Springer: Berlin.

Guzzetti F, Carrara A, Cardinali M, Reichenbach P. 1999. Landslide hazard evaluation; a review of current techniques and their application in a multi-scale study, central Italy. Geomorphology 31 : 181-216.

Jensen JR. 1996. Introductory Digital Image Processing: A Remote Sensing Perspective, 2nd edn. Prentice Hall: Upper Saddle River, NJ.

Havenith HB, Torgoev I, Meleshko A, Alioshin Y, Torgoev A, Danneels G. 2006. Landslides in the Maily-Say valley, Kyrgyzstan: hazards and impacts. Landslides 3: 137-147.

Lin WT, Chou WC, Lin CY, Huang PH, Tsai JS. 2005. Vegetation recovery monitoring and assessment at landslides caused by earthquake in Central Taiwan. Forest Ecology and Management 210: 55-66.

Malamud BD, Turcotte DL, Guzzetti F, Reichenbach P. 2004. Landslide inventories and their statistical properties. Earth Surface Processes and Landforms 29: 687-711.

Minetti L. 2004. Kyrgyz Republic proposed natural disaster mitigation project. 1st IDA Preparation Mission. Bishkek: Ministry of Environment and Emergency (MEE, not published).

Pelletier JD, Malamud BD, Blodgett T, Turcotte DL. 1997. Scale-invariance of soil moisture variability and its implications for the frequency-size distribution of landslides. Engineering Geology 48: 255-268.

Rathje EM, Kayen R, Woo KS. 2006. Remote sensing observations of landslides and ground deformation from the 2004 Niigata Ken Chuetsu earthquake. Soils and Foundations 46(6): 831-842.

Ridd MK, Liu J. 1998. A comparison of four algorithms for change detection in an urban environment. Remote Sensing of Environment 63: 95-100.

Roessner S, Wetzel HU, Kaufmann H, Sarnagoev A. 2002. Satellite remote sensing for regional assessment of landslide hazard in Kyrgyzstan (Central Asia). In Zweites forum katastrophenvorsorge, Tetzlaff G, Trautmann T, Radktke KS (eds). Deutsches komitee für Katastrophenvorsorge e.V. (DKKV): Boon; 433-441.

Rosin PL, Hervas J. 2002. Image thresholding for landslide detection by genetic programming. In Analysis of Multi-Temporal Remote Sensing Images, Bruzzone L, Smits PC (eds). World Scientific: Singapore; 65-72.

Shaoqing Z, Lu X. 2008. The comparative study of three methods of remote sensing image change detection. Proceedings of XXth ISPRS Congress, Istanbul, Turkey, 12-23 July. Papers Commission VII.

Song C, Woodcock CE, Seto KC, Lenney MP, Macomber SA. 2001. Classification and change detection using Landsat TM data: when and how to correct atmospheric effects? Remote Sensing of Environment 75: 230-244.

Stark CP, Hovius N. 2001. The characterization of landslide size distributions. Geophysics Research Letters 28(6): 1091-1094.

Teng SP, Chen YK, Cheng KS, Lo HC. 2008. Hypothesis-test-based landcover change detection using multi-temporal satellite images - a comparative study. Advances in Space Research 41: 1744-1754.

Torgoev IA, Alioshin YG, Havenith HB. 2002. Impact of uranium mining and processing on the environment of mountainous areas of Kyrgyzstan. In Uranium in the Aquatic Environment, Merkel, Planer-Friedrich and Wolkersdorfer (eds). Springer: BerlinHeidelberg-New York; 93-98.

Turcotte DL. 1997. Fractals and Chaos in Geology and Geophysics, 2nd edn. Cambridge University Press: Cambridge.

Vandenhove H, Quarch H, Clerc J, Lejeune J, Sweeck L, Sillen X, Mallants D, Zeevaert T. 2003. Remediation of uranium mining and milling tailing in Maily-Say district of Kyrgyzstan. Tacis Project No. SCRE1/No.38 Report.

Yang R, Wang Z, Li Z, Yang J. 2008. Remote sensing investigation and mechanism research of Tiantai landslide in Sichuan province. Proceedings of XXIth ISPRS Congress, Beijing, China, 3-11 July, Papers Commission VII. 